\section{EL JANO SOCIALISTA. \\ JUAN B. JUSTO Y EL LUGAR DE LOS \\ SÍMBOLOS EN LA POLÍTICA MODERNA}

THE SOCIALIST JANUS. JUAN B. JUSTO AND

THE ISSUE OF SYMBOLS IN MODERN POLITICS

\section{FRANCISCO J. REYES •}

Becario Postdoctoral del CONICET con sede en el Instituto de Humanidades y Ciencias Sociales, IHUCSO Litoral/ CONICET-Universidad Nacional del Litoral, Argentina.

E-mail: reyesfranciscoj@live.com

\section{Resumen}

El artículo analiza la forma en que un dirigente clave del socialismo argentino, Juan B. Justo, concibió el lugar singular que debían ocupar distintas manifestaciones de un fenómeno significativo de la política: los símbolos. Se argumenta que sus valoraciones y propuestas en torno a dicho problema resultaron siempre atadas a coyunturas cambiantes, evidenciando un carácter oscilante y demostrando el peso de dos fuentes: una cultura científica ampliamente extendida y la cultura política del socialismo de la Segunda Internacional. El corpus documental se compone de un amplio conjunto de intervenciones, para luego cotejarse con el aporte de otras voces provenientes del socialismo argentino que tensionan los postulados de dicha cultura política sobre el lugar de los símbolos, en general, y en la política argentina de inicios del siglo XX, en particular.

\section{Registro bibliográfico}

REYES, FRANCISCO J. "EI Jano socialista. Juan B. Justo y el lugar de los símbolos en la política moderna», en: ESTUDIOS SOCIALES, revista universitaria semestral, año XXVIII, n 55, Santa Fe, Argentina, Universidad Nacional del Litoral, julio-diciembre, 2018, pp. 65-90.

\section{Abstract}

The article analyzes the way in which a principal leader of Argentine socialism, Juan B. Justo, conceived the singular place that different manifestations of a significant phenomenon of politics had to occupy: the symbols. It is argued that their assessments and proposals around this problem were always tied to changing junctures, showing an oscillating character and demonstrating the weight of two sources: a widely spread scientific culture and the political culture of Socialism of the Second International. The documentary corpus is made up of a wide range of interventions, to then be compared with the contribution of other voices coming from the Argentine socialism that stress the postulates of said political culture on the place of symbols, in general, and in the Argentine politics of the early twentieth century, in particular.

\section{Descriptores · Describers}

culturas políticas / Juan B. Justo / nacionalismo / símbolos políticos / socialismo

political cultures / Juan B. Justo / nationalism / political symbols / socialism

Recibido: 15/01/2018 Aprobado: 04 / 05/2018 
"La unidad es siempre retrospectiva,

en el presente todo es intensidad y confusión...».

(Ricardo Piglia, Los diarios de Emilio Renzi. Un día en la vida).

\section{UN PROBLEMA CULTURAL DE LA POLÍTICA}

En enero de 1933 la revista Actualidad, vinculada al Partido Comunista (PC) de Argentina, llamaba a no convalidar el homenaje que organizaba el Partido Socialista (PS) para conmemorar la muerte de quien había sido su principal dirigente, Juan B. Justo. El argumento que ubicaba a esta figura en el plano de los traidores a la causa del movimiento obrero -en la línea de la crítica al «socialfascismo»-era que, en su testamento, Justo había expresado que su féretro debía estar cubierto con la bandera roja, símbolo del proletariado internacional, junto a la celeste y blanca de la nación argentina (CATTARUZZA, 2007: I74-I75) ${ }^{1}$. Una actitud de este tipo, pasado un lustro de su fallecimiento, sólo podía asumirse entre quienes todavía se consideraban miembros más o menos cercanos de una misma familia política que poseía un conjunto de referencias fundamentales que permitían establecer esa filiación común, ahora en disputa.

A continuación se desarrollará cómo, desde sus primeras intervenciones como intelectual y como militante, el lugar de los símbolos en la política moderna y, en particular, en el socialismo constituyó una inquietud permanente de quien fuera considerado «maestro» del ps. Este sentido pedagógico asignado a la labor de Justo, prolongado en la idea del partido-guía de una modernización político-cultural, se revela como uno de los vectores de este recorrido problemático. Pero las recurrentes valoraciones de Justo sobre banderas, emblemas e íconos resultan mucho menos lineales e inamovibles que lo supuesto por aquellos análisis que se abocaron a desagregar los supuestos de la llamada «hipótesis de Justo» (Aricó, 1999). En efecto, según una lectura que destaca la potencia pero también los prejuicios de una concepción «iluminista», evolucionista y, en última instancia, rígida de la política por parte de aquel, el socialismo habría fracasado en Argentina en su intento de articular al conjunto de los sectores populares en el momento de construcción de la primera democracia, a causa de una sobredeterminación doctrinaria expresada

${ }^{1}$ El autor agradece a Alejandro Cattaruzza por haber Ilamado la atención sobre la opinión comunista. 
por antonomasia en la obra y en el control partidario logrado por Justo y su grupo. En palabras de J.C. Portantiero, la principal dificultad estuvo dada por una incomprensión de la constitución compleja de los actores sociales (sus intereses materiales, sus preferencias políticas, su bagaje cultural) y, en consecuencia, en la opacidad que para esta visión revestía un fenómeno como el del radicalismo, movimiento nacional-populista que logró hegemonizar la experiencia democrática a inicios del siglo xx: «proceso en el cual los elementos simbólicos tienen tanta presencia como los desnudamente económicos» (PORTANTIERO, I999: 49-50).

La interpretación del dirigente socialista sobre la cuestión de los símbolos fue adaptándose al calor de distintos momentos conflictivos, en donde aquellos jugaron un papel destacado como catalizadores de posicionamientos antagónicos. Al mismo tiempo, se vislumbra un bajo continuo sintetizado en la consolidación del nacionalismo como fenómeno ideológico y cultural, desde la política popular hasta en los análisis de las elites finiseculares. Pero, lejos de no comprender la creciente centralidad de los símbolos, Justo intentó según el caso contrarrestar, potenciar y, por momentos, anular esta injerencia omnipresente, combinando sucesivamente registros que oscilaron entre el racionalismo fenomenológico positivista, la autorreferencialidad de ribetes emotivos y el más voluntarista discurso militante de propaganda.

Buena parte de la cuestión radica en la doble inmersión de Justo: en la «cultura científica» del fin-de-siglo, permeada pero no dominada absolutamente por el positivismo ${ }^{2}$, en la que se formó como estudiante de Medicina en la Universidad de Buenos Aires (I882-I888) y lector de los fenómenos sociales modernos; y en la emergente «cultura política» de unas izquierdas signadas por el internacionalismo obrerista con una rápida recepción de los postulados del socialismo de la Segunda

\footnotetext{
${ }^{2}$ Se sigue aquí a Oscar Terán, quien prefiere la noción de "cultura científica», "aquel conjunto de intervenciones teóricas que reconocen el prestigio de la ciencia como dadora de legitimidad de sus propias argumentaciones», por sobre la más tradicional de «positivismo», a la vez más restringida como canon intelectual y portadora de un conjunto de matices (TERÁN, 2000: 9). Trabajos como los de FRANZÉ (1993) o DOTTI (2009), postulan la pertenencia de Justo al positivismo y la aceptación de sus presupuestos sobre la transparencia de la realidad captada en su dinámica intrínseca, pero produciendo una obra teórica tensionada por la matriz subjetiva inherente a su compromiso político. Por su parte, Horacio Tarcus ha destacado que para Justo el socialismo operaba como agente de modernización al canalizar el mensaje científico hacia los sectores populares, rechazando así los fundamentos filosóficos (dialécticos) del materialismo marxista (TARCUS, 2013: 380-381).
} 
Internacional ${ }^{3}$. Si bien es cierto que la vulgata socialista se nutrió de esa cultura científica, también se produjeron tensiones y corrimientos expresados por las tendencias utópicas y hasta irracionalistas de una causa que pretendía regenerar la humanidad. Como lo expresara Justo, el socialismo era «el advenimiento de la ciencia a la política», pero al mismo tiempo «más que una teoría histórica, una hipótesis económica y una doctrina política, es un modo de sentir, pensar y obrar que vigoriza y embellece la vida de los individuos como la de los pueblos» (JUSTO, I902: 73 y 77). Un análisis en términos de culturas políticas debe subrayar, a diferencia de lo postulado por la "hipótesis de Justo», hasta qué punto la concepción y las valoraciones del «maestro» en torno al papel de los símbolos estuvo lejos de expresar de manera unívoca -y aún de forma mayoritaria- la política partidaria al respecto, en parte por las mismas oscilaciones señaladas. Su voz convivió constantemente con un sentido común militante y con una constelación de figuras que evidenciaban convicciones disímiles, modulaciones que enriquecen la trama de creencias, normas, sentimientos y valores, mitos, rituales y símbolos (SIRINELLI, I999: 46I-463) en que se involucraron los socialistas, las cuales explican en parte las derivaciones posteriores de la cultura política de las izquierdas en Argentina.

A partir de un heterogéneo corpus de fuentes -escritos periodísticos, formulaciones teórico-doctrinarias, conferencias partidarias- e incluyendo en un tercer momento a una miríada de voces alternativas que operan modulando los postulados socialistas, se propone un recorrido que excede a la figura de Justo pero que lo coloca como prisma privilegiado de ingreso a dicho problema de la naciente política de masas. Los socialistas debatieron tempranamente sobre un fenómeno propio de los procesos de construcción de solidaridades militantes que se dotaron de características distintivas dentro de un arco más amplio de significaciones y representaciones, estableciendo fronteras en los colectivos emergentes ${ }^{4}$ en la Argentina de inicios del siglo xx.

\footnotetext{
${ }^{3}$ Existe una gran cantidad de trabajos biográficos consagrados a Justo, tanto militantes como académicos, desde Luis Pan y Dardo Cúneo, entre los primeros, hasta José Aricó y Juan Carlos Portantiero, entre los segundos.

${ }^{4}$ Sobre la necesidad de las fuerzas políticas, en especial en sus orígenes, por dotarse de un conjunto de referencias simbólicas que los distingan dentro de culturas políticas más generales, lo que puede llevar a una ambigüedad en aquellas o a compartirlas con sus adversarios, ver BERSTEIN (2006).
} 
Las dos caras de Justo, como dirigente y pensador, terminan por superponerse al abordar su tratamiento de los símbolos y las emociones políticas que éstos despertaban en distintos sectores de la sociedad, vinculándose así con el Jano de la política moderna. En cierto momento, alrededor del proceso de democratización operado en Argentina y del impacto de la Gran Guerra en el movimiento socialista internacional, se cayó en cuenta que la marcha del progreso científicotecnológico no haría desaparecer aquellos elementos que habían sido pensados como pervivencias arcaizantes y que traccionaban voluntades. Resulta paradójico descubrir cuánto de esta inflexión de entreguerras sobre el «contagio de los símbolos» (BURRIN, I986) se encontraba preanunciada en las propuestas, los dilemas y los debates de un reconocido campeón del racionalismo político.

\section{II. «iNI ME IMPORTA NADA DE SÍMBOLOS!»}

En I9I2, luego de las primeras elecciones al amparo de una reforma que amplió la participación popular, se discutieron en la Cámara de Diputados los diplomas de los electos. En la ocasión, Justo refirió al «dolor inolvidable de ver llegar hordas, con la bandera argentina» que asaltaron los locales socialistas y anarquistas durante los festejos del Centenario de i9io. Ante la digresión, su par conservador Carranza exclamó que los hechos se justificaban porque «iEra la bandera celeste y blanca contra la roja!», replicando Justo que no había banderas rojas y que, en tal caso, no le importaban los símbolos 5 al tratarse de una violencia que juzgaba como signo del atraso de la "política criolla».

El debate muestra el carácter situado de las intervenciones de Justo sobre la cuestión de los símbolos como producto no sólo de un trabajo de reflexión sino también como argumentos del debate político. Los socialistas habían incorporado en su cultura política ciertos constructos científicos o pseudo-científicos y el lenguaje proveniente de la sociología y la psicología social que, en el cambio de siglo, actuaron como carnadura de las nuevas teorías de la democracia y del advenimiento de las masas, contradiciendo en casos sus mismas convicciones ideológicas, por ejemplo, desde el elitismo (Bellamy, 2008: 70-73 y ss.). El discurso de la Cámara

\footnotetext{
${ }^{5}$ En las obras completas de Justo el episodio se tituló «El mal uso de los símbolos» (1912), en: JUSTO (1947: 66).
} 
demuestra las oscilaciones valorativas de Justo sobre lo deseable de los símbolos políticos, en especial cuando se anteponía pasionalmente lo que definirá como "cuestiones de forma» por sobre las «cuestiones prácticas» del quehacer partidario atenidas a la «buena doctrina» ${ }^{6}$. En un punto que ha sido descuidado por los trabajos interesados en la dimensión simbólica del socialismo argentino -no así en los de otras expresiones de la Segunda Internacional (la mixtura de partidos y tradiciones nacionales o la dialéctica entre antagonismo y apropiación) (CALLAHAN, 2OIO; ANGENOT, I998; VAN GINDERACHTER, 2009; KORFF, I993)-, buena parte de los juicios negativos de Justo sobre los usos de las banderas estuvieron signados por los episodios violentos e iconoclastas generados por el ascenso del nacionalismo y las reacciones frente al mismo.

Durante los años de gestación del Ps, con el desafío por cómo dotarse de formas de propaganda que homogeneizaran las exiguas filas de la militancia y captaran nuevas adhesiones, una serie de artículos reflejan las ambigüedades de esta labor. De paso por Bélgica Justo pudo observar la potencia de los rituales de uno de sus partidos socialistas más admirados. Conmovido por el espectáculo, propuso en su crónica para el periódico partidario La Vanguardia (LV) adoptar «todos los actos del que realmente lo comprende y siente» para difundir la «nueva moral» socialista: grupos corales, bandas de música, flores, antorchas, luces de colores «del más bonito efecto", himnos como la Marsellesa o La Internacional, etc ${ }^{7}$. Estas referencias al mundo de lo sensible, capaz de calar en el imaginario popular, con sentidos positivos en la subjetivación política, la transmisión e incorporación de valores superadores de la "superstición», muestran a un dirigente inquieto por auscultar las formas de interpelación sobre lo que comenzaba a conocerse como las multitudes.

Un año después Justo ofreció en el periódico La Nación una réplica anónima al publicista austro-húngaro Max Nordau, autor del célebre libro Degeneración, quien había criticado las tendencias artísticas y la «filosofía del socialismo». El registro utilizado en este caso es el del intelectual-militante («pertenezco al partido obrero»), sin escatimar ironías. Para el europeo el socialismo había dejado de ser una teoría económica para devenir «una cuestión de ética y estética» («una revelación, dogmas, liturgias»); en cambio, para el argentino, Nordau no captaba la verdad de un fenómeno complejo al concentrarse en los «lados superficial y

6 Juan B. Justo, «La buena doctrina», Revista Argentina de Ciencias Políticas, t. X, 1915.

7 J.B.J., «La propaganda por el arte», LV, 03/08/1895. 
accesorio de las cosas». Según Justo, esa teoría económica -«base científica teórica» del movimiento obrero complementada por la biología, la sociología, los estudios de Darwin, Comte y Spencer- era incorporada como «sentido común» por el «proletariado ignorante» que elevaba su condición intelectual y moral. La evidencia la encontraba en las celebraciones del $\mathrm{I}^{\circ}$ de Mayo, cuando al colocarse los trabajadores «la flor roja en la buotonnerie» estaban expresando su reclamo fundamental por la jornada laboral de 8 horas $^{8}$. Según lo propuesto por G. Mosse para el estilo que se impuso de forma transversal a las distintas culturas políticas ${ }^{9}$, es posible afirmar que las implicancias de la estetización de la política no eran una preocupación ajena ni al Justo dirigente ni al intelectual. El problema parecía radicar en las derivas indeseadas de la pedagogía socialista o en la sustitución de los ritos tradicionales sin una superación racionalizada de sus formalismos. En su propuesta, los símbolos aportaban un componente festivo y de belleza que contribuía a la identificación de un colectivo socialista en constitución, pero no debían velar el núcleo de la tarea partidaria consistente en la progresiva autoconciencia del proletariado y de la ciudadanía en general. La representación de la causa no podía colocarse por encima de la causa misma.

En sus primeros textos programáticos, La teoría cientifica de la historia y la politica argentina (1898) y El socialismo (1902), hizo eclosión un catalizador fundamental de la visión de Justo en torno a los símbolos: el nacionalismo, como movimiento heterogéneo que se difundía en la sociedad. El mismo se expresó simultáneamente en la posibilidad de la guerra con Chile (I894-1902) que movilizó a la prensa, ligas nacionalistas y manifestaciones callejeras; las fiestas patrias con una liturgia enriquecida y convocante; también en la formulación de corrientes xenófobas que tuvieron su punto álgido en la sanción de la llamada «ley de residencia de extranjeros» $(\mathrm{I} 9 \mathrm{O} 2)^{10}$.

Justo no se refirió ahora a los símbolos del movimiento obrero, sino a los patrióticos, intentando conciliar convicciones políticas particulares (v. g. el socialismo) con un sentido de pertenencia territorial no excluyente (el nacionalismo);

\footnotetext{
8 «El socialismo y Max Nordau», La Nación, 27/07/1896.

${ }^{9}$ Ese «estilo político» consistió en la paulatina participación de las mayorías populares en proyectos políticos que podían estar encabezados por las elites, pero que cobraron impulso al generar una atracción fundada en una «formalización de las emociones» mediante mitos y símbolos, que aportaron una explicación de la vida social capaz de canalizar la acción de las masas (MOSSE, 2007: 267-276). ${ }^{10}$ Sobre el impacto de la «cuestión de la nación» en el socialismo, ver REYES (2018).
} 
en tanto, por otro lado, era la faz emotiva la que permitía comprender esta conjunción de lealtades aparentemente contradictorias expresadas en esos símbolos. Primero, apelando a la propia confesión de parte: «Amo al país en que vivo (...) me llamo argentino, y quiero que este sea el nombre de un pueblo respetado por sus propósitos sanos (...) veo que todavía cada pueblo tiene una bandera, y deseo que, mientras la humanidad no tenga una, la argentina o la sudamericana flamee en estas tierras» (JUSTO, [I898] 1920). Luego, mostrándose comprensivo con aquellas expresiones de sentimiento que los socialistas denominaron «buen nacionalismo", capaz de integrar a la población inmigrante y elevar la condición de los trabajadores «educando a las masas»: los «hombres sinceros, apegados a la tradición y los símbolos, para quienes nada es tan precioso como su bandera y su nombre nacional» (JUSTO, [1902] 1920: 72). Que en sus intervenciones doctrinarias Justo hiciera junto a la dimensión ética (valores, principios generales) un lugar a la dimensión patética (pasiones y afectos) con que cargaban los símbolos de identificación permite demostrar que el suyo no era un ciego racionalismo iluminista. Su apuesta a una pedagogía de las mayorías contemplaba que junto a los aspectos cognitivos -en su concepción, los principales- no se podía prescindir de las emociones que podían viabilizarlos ${ }^{11}$. Un problema que emergió poco después con la «querella por los símbolos» dentro del ps.

Este debate se suscitó en las filas partidarias luego de la represión gubernamental durante el I $^{\mathbf{0}}$ de Mayo de 1909 y ante la cercanía de los festejos del Centenario. En alza los discursos que asociaban la protesta social al carácter «extranjero» del movimiento obrero, una conferencia del ps desató fuertes reacciones alrededor de una cuestión: ¿eran compatibles la bandera roja, que representaba la causa de los trabajadores del mundo, con la bandera celeste y blanca, que remitía al sentimiento patriótico y a los argumentos de quienes justificaban la represión? En ese marco el gobierno nacional había comenzado a implementar una pedagogía patriótica en las escuelas públicas, a cargo del presidente del Consejo Nacional de Educación, José María Ramos Mejía, en donde el culto a la bandera nacional

${ }^{11}$ En algunos componentes fundamentales de lo político (conceptos, metáforas, símbolos y mitos) la importancia del factor emocional radica en el origen mismo de la racionalidad y la conciencia: «no resulta aceptable una rígida disociación entre el plano lógico-racional de la política y el plano sentimental e intuitivo, que se corresponde muchas veces con aquellos marcos de comprensión y acción» (FERNÁNDEZ SEBASTIÁN, 2009: 11-14). 
se nutría de fórmulas, cantos y formaciones. Estableciendo paralelismos con la «religión tradicional», muchos socialistas lo asociaron con formas de sacralización de los símbolos seculares. El periódico LV, dirigido por Justo, y la Revista Socialista Internacional (RSI), a cargo del abogado y profesor universitario Enrique Del Valle Iberlucea, fueron los espacios en donde se expresó la militancia, que la segunda incluyó como uno de los puntos a responder en la encuesta «Socialismo y patriotismo" (REYES, 2OI8) ${ }^{12}$.

A contramano de dos de las posturas definidas en el intercambio -socialistas «patriotas» frente a «internacionalistas» puros-, Justo se focalizó en el carácter más o menos superficial de los símbolos, pero sin dejar de tomar partido. En su experiencia, diferenciándose del cambio de siglo, «La bandera de la patria es la de todas las facciones y camarillas»; o sea, no sólo podía expresar sentimientos genuinos sino que también era objeto del uso y abuso por parte de los exponentes de la "política criolla», proclive a la violencia y, por eso mismo, encasillable en la Argentina que debía quedar atrás. Incluso las banderas nacionales oficiaban legitimando la expansión del capitalismo internacional al ondear en cada una de las sedes del mundo que tenían bancos como el de Londres ${ }^{13}$. El dirigente socialista intentó zanjar el dilema apelando a una realidad evidente: existía una «mayor intensidad de la emoción política local» expresada en el patriotismo («fatalmente nuestros sentimientos son más vivos por lo que nos toca más de cerca»), pero afirmaba que el internacionalismo se nutría del reconocimiento de los «prejuicios nacionales» del resto de la humanidad. En lenguaje cientificista, concluía que en "cuanto a las banderas, no tienen importancia»:

«De cualquier color, la bandera no sirve sino para sugestionar y arrastrar inconcientes. ¿Para qué ese color, que habla a los sentidos y excita los instintos de los hombres, sino porque no se quiere hablar a su inteligencia? (...) Tienen entretanto las banderas un valor negativo (...) Me gustaría más la sudamericana (...) Y prefiero la roja, porque significa que no me hipnotiza la azul y blanca, y presagia una humanidad libre e inteligente, sin banderas» ${ }^{14}$.

\footnotetext{
12 Sobre la pedagogía patriótica a cargo de Ramos Mejía y su vínculo con las inquietudes del Centenario, ver CASTRO (2010).

13 "La Patria», LV, 26/05/1909.

14 «La Patria y las banderas», LV, 19/06/1909.
} 
La invectiva muestra en un contexto de conflictividad a un Justo atrapado en su compromiso militante, al decantarse por el símbolo internacionalista antes que por el nacional o denostando tout court a los emblemas identificatorios. En un nivel analítico presuntamente objetivo, esta actitud se fundaba en la terminología propia de la psicología social: fatalidad, sugestión, inconsciencia, excitación de los instintos, hipnotismo. Expuestos a la manipulación de sus líderes o anulando sus aptitudes como parte de una masa en efervescencia, los sujetos individuales perdían su autonomía al fundirse en la multitud que actúa por imágenes sugestivas (los símbolos) y subleva sus pasiones (BELLAMY, 2008). Resulta superficialmente paradójico que dos intelectuales formados en la "cultura científica» del fin-de-siglo, los médicos Ramos Mejía y Justo, coincidieran en sus concepciones, uno dentro y otro frente al Estado ${ }^{15}$. ¿Eran los símbolos sólo un mal o un mal necesario? ¿La respuesta era la misma para el intelectual que para el político, o estas figuras podían superponerse sin solaparse?

En su obra de mayor aliento, Teoría y práctica de la Historia, Justo profundizó en esta ambigüedad de los símbolos, atada a la evolución de las formaciones sociales. Los "símbolos tradicionales» se habían desarrollado legitimando las distintas instancias de dominación social, al gozar de una sanción religiosa que otorgaba un aura a la autoridad. Pero el Estado, la autoridad por excelencia, desarrolló en paralelo una autonomía -para mantener el orden social, privilegios de clase y sobre todo para dirigir la guerra ${ }^{16}$ - expresada en sus propios símbolos (Justo, 1909: 155-157). El advenimiento del proletariado como moderno sujeto de la historia tampoco escapaba a esta lógica: «Al elevarse la cultura del pueblo trabajador y nacer sus aspiraciones a un estado social superior, critica él los dogmas y símbolos aderezados por la clase dominante, comienza a crearlos por sí mismo» (Justo, I909: 496). Los símbolos vuelven a ser un elemento funcional gracias a su capacidad para sintetizar la lucha entre el viejo y el nuevo orden civilizatorio que se despliega con inevitabilidad biológica. Pero la misma fluidez del proceso histórico llevaría a abandonar estas cristalizaciones que, llegado el momento, pue-

${ }^{15}$ Sobre el impacto de estas teorías en Ramos Mejía, ver TERÁN (2000: 83-133).

${ }^{16}$ Destacaba: «Para excitar las masas a la guerra, se cultivan sus sentimientos colectivos más próximos a la animalidad, la superstición miedosa, el instinto de raza, el fanatismo patriótico y allá van ellas, como el toro contra el trapo rojo, ciegas y enfurecidas, tras la bandera o el símbolo religioso» (JUSTO, 1909: 114). 
den tornarse regresivas aún condensando la buena nueva del socialismo, ya que «idea alguna puede consolidarse en dogma, traducirse en símbolos, manifestarse en ceremonias y ritos, sin riesgo de inmovilizarse, de caer en el formalismo, en la vaciedad, en la simulación». La «emoción» suscitada por la causa justa, llevada al extremo, también devenía «inerte fatalismo» (JUSTO, 1909: 508).

El exabrupto de I9I2 en la Cámara se comprende a la luz de esta voluntad desacralizadora incluso de las propias convicciones políticas (PRISLEI, 2000: 59-6I). A esas alturas, el antagonismo ideológico ya se expresaba en la política simbólica del gobierno nacional: a través de la sanción de la llamada «Ley de Defensa Social», el año del Centenario se prohibió toda «bandera, emblema o distintivo» del movimiento obrero en el espacio público asociado a la «revolución social» ${ }^{17}$.

\section{BANDERAS EN DEMOCRACIA}

El proceso de democratización abierto en 1912 operó un cambio del lugar ocupado por el ps en el concierto político argentino. Una serie de novedades fueron decisivas: la representación parlamentaria que abrió nuevas expectativas, y el ascenso de un movimiento nacional-popular como el radicalismo que hegemonizaría electoralmente a las mayorías; en otro frente, la conmoción que significó la Gran Guerra y su colofón en la Revolución Rusa, que impactó en el corazón de la causa socialista y tuvo consecuencias en la resemantización de sus símbolos. Se ha afirmado que ante este nuevo panorama Justo se decantó por una reafirmación de sus convicciones «mediante su desciframiento desde el catálogo nocional preexistente» (GELI y PRISLEI, I993: 35$)^{18}$. Esto reflejaría una inadaptación o una adecuación problemática de su "cosmovisión» a dicho contexto. No obstante, en su actitud frente a esa omnipresencia de los símbolos en una democracia de masas, por debajo de esas nociones forjadas en el complejo cruce de culturas en las que abrevara, antes que una incomprensión se vislumbra una apuesta cambiante, aflorando una advertencia de ciertas tendencias que en los años de la entreguerras se volverían una realidad más patente: un nacionalismo más agresivo y una izquierda potencialmente autoritaria.

\footnotetext{
17 «La bandera roja y la defensa social», LV, 11/11/1910.

18 Este planteo es compartido por otro trabajo centrado en las posiciones económico-doctrinarias de Justo y el PS ante la Gran Guerra (POY, 2014).
} 
En cuanto a lo primero, Justo fundamentó en la Cámara de Diputados en I9I6 un proyecto de ley firmado por el grupo parlamentario socialista como forma de conmemorar el Centenario de la Declaración de Independencia. Los símbolos aparecen nuevamente como un eje de su argumentación, de la mano de un "patriotismo más sano e inteligente» capaz de integrar a argentinos y extranjeros sin caer en la «aberración» del antipatriotismo. No se niega su importancia, pero aquellos son considerados una vez más «manifestaciones externas», que podían desviar la atención de lo fundamental: la elevación material, intelectual y moral de la población:

"creemos que nuestro símbolos nacionales: las manos que se estrechan, el gorro frigio, las palabras «libertad e igualdad, los acordes del himno, los colores azul y blanco, son de los símbolos más simpáticos (...) Los aceptamos y hasta amamos; pero comprendemos esto: que cuando se trata de símbolos, de cosas materiales, que no son la convicción, sino cosas externas (...) que se pueden usar y agitar con fines interesados, hay que tener mucha moderación y cordura en la apreciación de su uso y no hay que dejarse sugestionar por ellos» (Justo, [1915] I933: 79-82).

El lenguaje de la ciencia finisecular se combinaba con el intento de conciliación para evitar que el socialismo se colocara fuera de la comunidad política legítima. Se proponía además exaltar la misión civilizatoria del ps luego de la «barbarie» que había sido justificada por las banderas argentinas. Pasaba de la denuncia del «mal uso» a la necesidad «de ser muy moderados en el uso de los símbolos». Una tibieza que sería tomada como excusa por la UCR -fuerza que exteriorizaba un verdadero culto a los símbolos nacionales- durante la campańa presidencial de i9ı6. Una instancia en donde los mítines, los desfiles en las calles y los discursos se proponían afianzar lealtades e identificaciones que necesariamente debían ir más allá de los militantes (Palermo, 20I6: 4I-43). De allí la centralidad de la cuestión de la nación en la incipiente democracia argentina, un desafío que tuvieron que enfrentar con énfasis singulares aquellos partidos socialistas que provenían de una cultura política internacionalista pero que no renunciaban a entroncarse con tradiciones nacionales.

Por ejemplo, para el órgano del radicalismo de la Capital Federal era casi una blasfemia que ciertos partidos que se consideraran argentinos se pronunciaran en contra del «excesivo uso» de la bandera y el himno patrios. A diferencia de los socialistas, para los radicales las representaciones de la causa eran la causa misma, 
por eso la apelación "partidista» de los «símbolos patrióticos» sería para el "pueblo soberano (...) uno de los ejercicios más justificados de todos los países» ${ }^{19}$. El presidente del Comité Nacional de la UCR, José Crotto, volvería más concreta la referencia en su discurso de la Convención Nacional que sancionó la candidatura de Hipólito Yrigoyen. Al juzgar a sus adversarios, se refirió a los socialistas como «enemigos de la nacionalidad, partidarios de la desorganización social y enemigos de la bandera, que es nuestro órgano, nuestro símbolo de la patria ${ }^{20}$. Estas disputas interpartidarias por los símbolos nacionales continuaron ejerciendo como tópicos conflictivos dentro de la propia cultura política de los socialistas. Pero Justo esgrimió una respuesta desde el ps a tono con una predica más regular que criticaba a su vez el "patrioterismo» ensalzado por los radicales ${ }^{21}$. En referencia al discurso de Crotto, no dudó en asegurar que existía «un abismo de ideas y sentimientos» que separaba al PS de la UCR, por el culto «inconsciente» que desde la segunda se hacía de la bandera argentina. Esto conducía a las violencias y descalificaciones que habían sufrido los socialistas en el Centenario o con el triunfo para senador de Enrique Del Valle Iberlucea en I913, cuando su presencia en la Cámara alta fuera impugnada por el mismo Crotto a razón de la previa publicación de la encuesta "Patria y socialismo» ${ }^{22}$.

Como en el caso general del nacionalismo, debe consignarse que aquellos trabajos que remiten a la «incomprensión» por parte del socialismo del fenómeno nacional-popular del radicalismo y de su uso de los símbolos han prestado escasa atención al carácter más bien defensivo de las formulaciones de aquel. Las opiniones del mismo Justo sobre los símbolos eran producto de una evolución de sus ideas y de una adecuación a cambios conflictivos. Es lo que se trasluce en sus reflexiones al calor de la Gran Guerra, cuyas consecuencias excedieron al fracaso de la Segunda Internacional para evitar una conflagración. En una reevaluación de sus certezas previas, Justo se preguntó por los valores éticos que podrían rescatarse y aquellos que habían quedado atrás, cuando «toda la ciencia de la historia» en que se fundaban no pudo prever la catástrofe. No dudó en encontrar uno de

\footnotetext{
19 "La bandera y el himno», El Radical, 23/01/1916. Sobre la temprana identificación de la UCR con una «causa nacional» y sus usos de los símbolos patrios, ver REYES (2016).

20 Transcripto en: «La Convención Nacional», El Radical, 21/03/1916.

${ }^{21}$ Sobre las críticas del socialismo respecto del nacional-populismo del radicalismo, ver MARTíNEZ MAZZOLA (2008).

22 «Política nacional», LV, 23/03/1916.
} 
los huevos de la serpiente en los principios nacionales que se inculcaron por «el respeto, cuando no en el fanatismo, por los mismos símbolos» (JUSTO, I9I6: 28I), retomando lo postulado en Teoría y práctica de la Historia.

Sensible a las emociones tras la guerra, aseguró para el I $^{\mathbf{0}}$ de Mayo de 1918 que se estaba experimentando una de "esas grandes crisis del sentimiento» que volvía más necesaria aún la construcción de «un gran sentimiento de solidaridad social y una plena conciencia histórica para comprender y orientarnos en medio del caos en que se debate el mundo» (Justo, [I9I8] I933: I55). Pero producida la Revolución Rusa, que trajo aparejada la división de las filas socialistas, primero con la escisión del Partido Socialista Internacional y luego con la creación del PC, todavía en su discurso del $\mathrm{I}^{\mathrm{o}}$ de Mayo de 1922 señalaba positivamente la «emoción común de solidaridad y amor» mediante una conmemoración celebrada por socialistas, sindicalistas revolucionarios, cooperativistas, comunistas y anarquistas (JUSTO, [1922] 1947: 376). No obstante, ante la guerra y un socialismo comunista que tomaba perfilaba ciertas características presentes en la propia cultura política que juzgaba perniciosas, Justo pronunció tres conferencias sobre «el momento actual del socialismo». Con referencias a su propia experiencia, el diagnóstico de la Revolución que despertaba nuevamente la utopía de redención proletaria por la toma del poder se vio permeada por un fuerte escepticismo respecto de concretar este proceso desde el Estado. Su intuición sobre el bolchevismo se asoció a su análisis previo del nacionalismo en el peligro que suponía la «superstición autoritaria» incubada en el deseo de la «sociedad nueva y perfecta». Las nociones de la cultura científica finisecular volvían a penetrar las dos caras del Jano (Justo, [1920] 1947: 316).

Pulsiones irracionales de unas masas que se expresaban en el «fetiquismo político» promovido desde el Estado y con el que siempre identificó a los símbolos, así como a las pasiones susceptibles de manipularse desde arriba, como la experiencia del general Boulanger que viera en Francia, la UCR criolla o los soviets rusos. La solución se encontraba, según él, en el «método de acción socialista» pero adaptado a los nuevos tiempos, conjugando el «estado subjetivo» de una «nueva moral» con la clásica «conducta voluntaria y consciente» preconizada por el PS (JUSTO, [I920] 1947: 333). A conclusiones similares había arribado en las primeras décadas del siglo Robert Michels, discípulo socialista de Max Weber, en su análisis del funcionamiento de los partidos políticos en la democracia moderna, centrado en la socialdemocracia. Para éste, la «supervivencia atávica» de ciertas tendencias latentes se expresaba en el «culto de la veneración entre las masas» hacia sus líderes o hacia 
sus símbolos, sea la bandera roja o un crucifijo. Esta liturgia moderna se debía a una necesidad moral, una «superstición», "poderosa influencia de sugestión» a partir de la manipulación de las masas por las elites (MICHELs, [I9II] 20I7: IO7-II2) ${ }^{23}$.

En ese contexto de entreguerras, las enseñanzas de los años precedentes llevaron a Justo a reformular algunas de sus posiciones sobre la política simbólica del PS. Sus últimas intervenciones se dieron a la luz de un fenómeno que, si bien no dejaba de remitir a los viejos desafíos partidarios o a los conflictos de los Centenarios, evidenció la virtual omnipresencia de los símbolos en el marco de una política de masas de la que el socialismo fue uno de sus protagonistas. La vida militante en democracia fue el leitmotiv. Primero, al protestar por la negativa de la escolta militar a rendir honores durante el cortejo fúnebre del fallecido diputado socialista Eugenio Albani. El féretro había sido cubierto con la bandera roja, otorgándole un sentido partidario que generó el rechazo del jefe militar al alegar que sólo se respetaría el protocolo con la exclusividad de la bandera argentina. Justo recordó entonces que poco importaba el «color de los trapos que puedan cubrir el ataúd en los casos de los honores» y que para el ps la coexistencia de ambas banderas no era motivo de conflicto y el mismo partido podía "prescindir de banderas en sus ceremonias», como se ejemplificara con la ley de Defensa Social, y, por último, la roja se desempañaba al mismo tiempo como el emblema de una potencia internacional -la Unión Soviética- que respetaba la autonomía de los pueblos. De forma provocadora, dejaba vislumbrar que la barbarie siempre había provenido del culto a los símbolos nacionales y que la «simplificación del ceremonial» traduciría el «progreso intelectual y moral» encabezado por el $\mathrm{Ps}^{24}$.

¿Ello significaba que, cuando era más necesario reforzar simbólicamente el compromiso de los seguidores, el Ps renunciaba a reproducir sus ritos partidarios ${ }^{25}$ ? ¿Acaso radicales, comunistas y nacionalistas no hacían lo propio con sus emblemas y banderas en cada uno de sus actos, dato transversal a las distintas culturas políticas en su uso de los símbolos? Finalmente, ¿sigue siendo posible afirmar que Justo pensaba y actuaba guiado por los prejuicios iluministas y se mostrara insensible a la dimensión simbólica de la política?

\footnotetext{
${ }^{23}$ Un análisis de las formulaciones de Michels en torno a los símbolos, en KORFF (1993: 106-114).

24 "La bandera roja y la bandera argentina. No habrá conflicto», LV, 11/05/1924.

${ }^{25}$ Sobre los ritos fúnebres del socialismo argentino y los símbolos que allí se ponían en juego, ver SERAS (2015).
} 
El último texto escrito por Justo encontrado luego de su muerte era un «Programa de acción para las Juventudes Socialistas» cuya factura muestra una intervención militante donde se abogaba por una política simbólica. La propedéutica para la propaganda socialista era introducida con una comparación entre el contexto moral y cultural de la década de 1920 y su propia experiencia formativa. La confianza en la función del ps como «escuela» confería a esa juventud una tarea fundamental: la "participación en las manifestaciones públicas del Partido Socialista, que debieran hacerse con estandartes y banderas y, si lo tienen, de uniforme». De forma similar a sus tempranas reflexiones europeas, concluyó que con el esfuerzo por «crear una gran fiesta genuinamente socialista (...) con un poco de sentimiento y otro poco de imaginación artística, se llegaría a organizar una fiesta de gran emotividad y significado» (JUSTO, [1927/1928] 1947: 406).

Como en el arte y en la «buena doctrina», la "forma» podía acudir en ayuda del «fondo» para conmover y movilizar las voluntades de las masas, complementando la misión histórica del partido-escuela: el esclarecimiento del proletariado y la civilización de las prácticas ciudadanas. En el agitado clima de entreguerras, Justo se mostraba contemporáneo al estilo político de su tiempo a la vez que como exponente de una cultura política forjada previamente, al abrevar en el fenómeno más general de la estetización de la política y reconocer el lugar preeminente de los símbolos. Sin embargo, un breve recorrido por otros exponentes de esa cultura permite calibrar mejor la forma en que se resignificaron buena parte de las convicciones y creencias expresadas en los símbolos.

\section{VARIACIONES Y DERIVAS DE UNA CULTURA MILITANTE}

Las oscilaciones de Justo en torno al lugar de los símbolos en la política moderna convivieron tanto con otras visiones expuestas por referentes partidarios que en casos llegarían a mostrar una disidencia insalvable con la conducción del PS, como con un sentido común que condensaba las representaciones imaginarias de la causa socialista. En sincronía con debates propios de la política argentina y otros de carácter internacional que afectaban a sus formulaciones, estos dos vectores permiten definir mejor el terreno sobre el cual operaron el pensamiento y los argumentos políticos de Justo, a la vez que ofrecen una lectura arborescente de la cambiante cultura política de los socialistas. 
Fue la ritualización del $\mathrm{I}^{\mathrm{o}}$ de Mayo la que instaló como un acervo irrenunciable los principales símbolos e imágenes del internacionalismo obrero y su mensaje utópico, más aún en un país donde el socialismo coaguló por la confluencia de distintas asociaciones étnicas. Esta naciente liturgia evidenciaba el carácter difuso de la cultura política en que se inscribió el ps así como la forma en que el color rojo de la bandera se convirtió en el «significante trascendental» del socialismo, exaltado periódicamente como símbolo de la transformación del mundo ordinario en una realidad moldeable por un nuevo sujeto colectivo (ANGENOT, I998). Este fondo semiótico permite comprender la polémica de Justo con Nordau en torno a la ritualidad socialista así como hasta qué punto ese simbolismo contracultural era necesario o excesivo. Las representaciones sobre el $\mathrm{I}^{\mathrm{o}}$ de Mayo se revelaron pletóricas en un conjunto de metáforas dicotómicas cargadas de valoraciones que simplificaban las aristas más complejas del mensaje partidario (una filosofía de la historia implícita, una doctrina fundada en la lucha de clases, la centralidad del partido en la acción política, etc.). Como lo expresara Enrique Dickmann al filo del 1900: «Las fiestas son símbolos. Símbolos del Pasado, símbolos del Presente, símbolos del Porvenir». En esta clave, la Fiesta del Proletariado no podía ser sino «el símbolo de la Paz, del Amor y es también el símbolo de la Igualdad (...) de la Fraternidad entre pueblos» ${ }^{26}$.

El ensayo más ambicioso por sistematizar las ideas de Justo sobre los símbolos estuvo a cargo de Adolfo Dickmann, según el cual las sucesivas intervenciones del «maestro» habrían dado lugar a un "concepto» sobre la cuestión. En «Los argentinos y el principio de nacionalidad» (I9I6) identificó el núcleo de lo abordado por Justo en sus intentos por conciliar las banderas roja y argentina. La operación, en medio de los «sentimientos contradictorios que permanecerán latentes en las masas populares» por el desarrollo de la Gran Guerra, no dejaba de incubar una cierta ilusión de coherencia retrospectiva en las concepciones de Justo: solamente se mencionan sus textos e intervenciones en donde los símbolos, «muy al contrario de excluirse, se complementan y se agrandan con su mutuo contacto» (DICKMANN, 1933: 13 y 36). Al retomar opiniones de otros dirigentes, el texto convirtió a Justo en fuente de la política partidaria sobre los símbolos. En este punto, las interpretaciones filiadas en la "hipótesis de Justo» resultan certeras, ya que no se advierte aquí el carácter conflictivo del problema y la de Justo se presenta como una voz que

${ }^{26}$ Enrique Dickmann, «Aurora de Mayo», LV, 01/05/1899. 
irradia sin fisuras al conjunto de la formación partidaria. Sin embargo, un breve repaso sobre distintas opiniones de las primeras décadas del siglo $\mathrm{xx}$ al calor de diferentes contextos ofrece un panorama menos unánime y exhibe las inflexiones que comenzaron a operarse en la cultura de los socialistas.

Un momento clave fue la querella por los símbolos. Pero en la encuesta de la RSI, en la que se consultara sobre el posible antagonismo de las banderas, las respuestas fueron heterogéneas y abiertamente divergentes con la opinión de Justo. Así lo expresaron las intervenciones de dos socialistas "patriotas» como Antonio De Tomaso y, sobre todo, Alfredo Palacios. Para el primero, cercano a Justo, la pluralidad de sentidos asignados a la bandera roja la volvía un «símbolo representativo multiforme», mientras que la argentina expresaba la «unidad nacional», de lo cual se desprendía que los «símbolos tienen un valor sociológico innegable» ${ }^{27}$. En una sociedad en la que comenzaban a constituirse colectivos que representaban ciertos intereses se volvía necesario comprenderlos para operar sobre la realidad. Más detallada fue la respuesta de Palacios, quien desde su ingreso al ps se había mostrado como un espíritu independiente. A su entender, "las banderas son símbolos, signos, a los que se atribuye un sentido convencional y por virtud de los cuales conocemos, por representación, un conjunto de sentimientos o ideas». Fundándose en escritos consagrados, de Marx a Jean Jaurès, consideraba necesario promover tanto la roja como la nacional, ya que «representan ideas distintas» ${ }^{28}$, mutuamente inconmensurables. Palacios insistió luego en un cambio en la política simbólica del partido durante el XII Congreso de 19I4, un año antes de su expulsión y del proyecto de ley respecto del uso moderado de esas «cosas externas». Anticipándose a la crítica de la UCR, Palacios presentó una moción para que el PS empleara la bandera argentina en sus manifestaciones públicas, demostrando que el socialismo no era incompatible con un «buen nacionalismo», pero ante la réplica del propio De Tomaso de que ello se efectuara sólo cuando se derogara la Ley de Defensa Social que prohibía la bandera roja, la propuesta terminó postergándose sin ser aprobada ${ }^{29}$. Enmarcada por los Centenarios, la cuestión nacional se ubicó

\footnotetext{
${ }^{27}$ Antonio De Tomaso, «Patria y Socialismo», RSI, 25/05/1909, t. 2, nº 1, pp. 29-32.

${ }^{28}$ Alfredo Palacios, «Patria y Socialismo», RSI, 25/05/1909, t. 2, no 1, pp. 35-39.

29 «EI XII Congreso del Partido Socialista», LV, 25-26/05/1914. Durante la sesión Justo terminó apoyando la postura de De Tomaso. Sobre las particularidades de las posiciones de Palacios al interior del PS y su salida, ver el artículo de Carlos Herrera en este dossier.
} 
en el centro de los debates ideológicos y las creencias sedimentadas sobre el papel de los símbolos emergieron como manzana de la discordia, revelando el desafío de la democracia de masas.

Aristas diferentes presenta el caso de Manuel Ugarte, escritor modernista que ofició de representante argentino en los congresos de 1904 y 1907. Promotor como Palacios de la incorporación de los motivos patrióticos, el sesgo marcadamente personal de sus intervenciones dio lugar a otra salida escandalosa. Los motivos esgrimidos en su Manifiesto contra el ps colocaron en un primer plano la estetización de la política como contracara de lo que consideraba la primacía del materialismo en la doctrina partidaria. Acusado de "confusionismo doctrinario» y un «excesivo apego al atavismo patriótico», se decantó por «las cosas del sentimiento» apelando al idealismo de Jaurès y achacó que «lo que el partido socialista disminuye con su actitud no es solamente la envoltura vistosa sino la columna vertebral de la idea». $\mathrm{Su}$ argumento se volvió directamente contra la posición de Justo sostenida en el debate parlamentario de I9I2, al considerar Ugarte que comprometía la defensa de la propia nacionalidad - «nuestro colores gloriosos y respetados, ante los cuales me inclino»-, a la que concebía como condición de posibilidad de la causa socialista. La desaprensión hacia los símbolos, a su entender, se debía a la obsesión partidaria por la «unidad suprema», mientras el artista comprometido comprendía que allí se jugaba mucho más que un signo externo de su lucha (UGARTE, I9I4: 50, 96 y 103 $)^{30}$. Desde entonces, su nacionalismo opacó sus convicciones socialistas y en 1916 publicó el artículo "La bandera y el himno», verdadera apología de los símbolos nacionales: «lo que aquí se impone antes que nada es difundir y afianzar el sentimiento nacionalista por medio del razonamiento, el color, el sonido, los recuerdos y cuanto concurre en el alma esa maravillosa emoción colectiva que se llama patriotismo». El ejemplo que creía necesario imitar era el de su denostado Estados Unidos, que «entrega los símbolos a la masa popular», porque la bandera y el himno serían «en realidad, la mirada y la voz de un conjunto nacional» que debía propagarse «hasta invadir todos los cerebros y todos los corazones para amalgamarlos». Su contrapuesto era la bandera roja socialista, «símbolo de ensueños y de la negación de la patria» ${ }^{31}$, en momentos en que la Gran Guerra interpelaba de

${ }^{30}$ Para la tensión entre las convicciones estéticas modernistas de Ugarte y su compromiso político, ver EHRLICH (2006/2007); en cuanto al affaire Ugarte en el PS, MARTíNEZ MAZZOLA (2008: 223-233). ${ }^{31}$ Manuel Ugarte, «La bandera y el himno», La Patria, 22/01/1916, en: UGARTE (2013: 177-179). 
forma excluyente los sentimientos nacionales ${ }^{32}$. Una inversión de la carga valorativa de las banderas que tensionaba a la cultura política del socialismo

La otra cara del desafío la ofreció la Revolución Rusa y sus consecuencias para la agitada familia socialista, el desprendimiento de sectores que dieron forma a los PC y que reinterpretaron tanto la utopía revolucionaria y su iconografía. La creación del Partido Socialista Internacional en I9I8 inició en Argentina el camino hacia el comunismo mediante la disputa de la legitimidad histórica del ps por la enunciación de la causa socialista (CAMARERO, 20I7: I7I-I75). Con la llegada de las primeras noticias de Rusia, el senador Enrique Del Valle Iberlucea ofreció en una serie de conferencias entre I9I7 y I92I una lectura del fenómeno revolucionario en una clave que anticipaba al naciente comunismo instalándolo en una filosofía de la historia de carácter trascendente.

Este profesor universitario, referenciado en el marxismo segundointernacionalista que dirigiera sucesivos órganos teóricos del $\mathrm{Ps}^{33}$, había incluido el tópico de las banderas en su encuesta de la RSI, asegurando que «la bandera roja simboliza» la «esperanza de redención» de los trabajadores ${ }^{34}$. En contraposición a la deriva nacionalista de Ugarte y la conciliación simbólica de Palacios, Del Valle profundizó la tendencia al monocromatismo rojo acicateada por la escatología revolucionaria. Su primera impresión fue la de una causa emancipatoria y democrática renovada -en marzo de 1917 se lee: una «Rusia liberada de la tiranía zarista a la sombra de la bandera roja»- por el triunfo de un sujeto histórico mesiánico: el «proletariado universal». Poco después ubicaba a la Revolución entre los «grandes acontecimientos» que continuaban la tradición socialista:

«Los hechos acaban de demostrar que no era el peligro lo que bajaba de los Urales. Era la bandera roja que flameara durante dos meses en París a partir del I8 de marzo de i87i (...) Esa bandera, símbolo de unión y de la fraternidad de todos los pueblos del mundo» (DEL VAlLe IBERLUCEA: 1934: 3I Y 37).

\footnotetext{
${ }^{32}$ Sobre la variedad de expresiones de una cultura política nacionalista acicateada por las consecuencias de la Gran Guerra, ver TATO (2016).

${ }^{33}$ Las particularidades del marxismo de Del Valle Iberlucea, de corte positivista y no desprovisto de una ética redentorista, en TARCUS (2013: 448-449).

${ }^{34}$ Enrique Del Valle Iberlucea, «La «Internacional»», RSI, nº 8, 14-15/07/1909.
} 
Luego, cuando su adhesión a la Tercera Internacional comunista y su apoyo al sector «tercerista» dentro del ps generó su proceso de desafuero del Senado, poco antes de su muerte ${ }^{35}$, la interpretación de Del Valle tradujo localmente el campo de batalla simbólico de la Revolución. La lucha por el monopolio de los símbolos de una cultura política y la apropiación bolchevique de la bandera roja operaron un vuelco mediante el cual se la invistió de una nueva sacralidad (FIGES y KOLONITSKII, 200I: 17-19). Proyectando una imagen que no dejaba de inspirarse en «las doctrinas del Partido Socialista», anunció en 1920 que la «aurora de un nuevo mundo» encabezado por los soviets iniciaba la concreción de aquella esperanza de redención, la «ciudad del porvenir», la «ciudad sońada», la «república ideal». Una polis proletaria que «levanta con vigor la bandera roja, hoy adornada con los símbolos del trabajo, destinada a ser la bandera gloriosa de la república internacional de los comunistas» (DEL VALLE IBERLUCEA, I934: 90-9I).

Inmerso en el tiempo utópico de la Revolución Rusa y el triunfo comunista, Del Valle describía una resignificación duradera del símbolo de la cultura política de los socialistas: la bandera roja coronada ahora por la hoz y el martillo. Por esos ańos, Justo volvía en sus conferencias sobre el fetichismo político y las posibles evoluciones autoritarias de ese nuevo régimen, reavivando sus inquietudes en torno a los procesos de sacralización de una causa política con que condenaba al nacionalismo militante e, incluso, al propio socialismo permeado de reminiscencias religiosas.

\section{REFLEXIONES FINALES: ¿POR QUÉ IMPORTAN LOS SÍMBOLOS?}

A inicios de 1928 Justo murió e inmediatamente se organizó su funeral en la Casa del Pueblo en la Capital Federal. Como recordaban los comunistas de la década de 1930, el «maestro» socialista había sido claro en su testamento: «Deseo que mis exequias sean muy sencillas, que en ellas no haya discursos y que sobre mi féretro estén la bandera roja y la bandera argentina, o ninguna bandera» (cit. en CúNeO: 1997: 466). El epitafio era coherente con sus tribulaciones a lo largo de tres décadas en su vinculación con los símbolos políticos. Según lo visto, Justo

${ }^{35}$ El compromiso con los grupos juveniles de la izquierda partidaria, favorable a los «consejos obreros», llevó a debatir el posicionamiento del PS ante la Tercera Internacional en el IV Congreso Extraordinario a inicios de 1921, que concluyó con la expulsión de los dirigentes terceristas (CAMARERO, 2017a: 187-195). 
era perfectamente consciente del lugar de los mismos en la ritualidad partidaria. Se ha argumentado que símbolos como las banderas, los himnos o las consignas se encontraban cargados tanto de aspectos morales y estéticos (un «ethos») como de aspectos cognitivos y existenciales (una "cosmovisión») que habían arraigado, pero también se reformulaban constantemente en las distintas culturas políticas. Asentimiento cognitivo y entrega emocional (GEERTZ, 2006: II8-I3O).

En tanto Justo se desempeñaba como senador nacional, el presidente de la Cámara decretó ante su fallecimiento que la bandera argentina se izara a media asta durante tres días, interviniendo así el Estado en sus funerales. Pero los centros y asociaciones socialistas pusieron en marcha una verdadera apoteosis. Algunos propusieron izar las banderas rojas a media asta en los locales, marchar con las mismas durante el desfile hasta el cementerio de la Chacarita o que los niños asistentes lucieran claveles rojos. De acuerdo a los comunicados publicados en $L V$, se trataba de honrar "con fe y con amor» a quien fuera el «alma del proletariado argentino", «apóstol del socialismo», «maestro de la juventud», que representaba los «ideales de redención proletaria» y Enrique Dickmann lo exaltó en su discurso fúnebre al estatus de «hombre simbólico», porque «interpretó y representó a un pueblo y a una época» ${ }^{36}$. En contradicción con los deseos de Justo, el féretro primero fue envuelto sólo con la bandera roja del Comité Ejecutivo Nacional del Ps, pero luego en la carroza fúnebre se agregaron las banderas argentina y la multicolor de las cooperativas ${ }^{37}$. Lo que para los comunistas luego sería connotado como traición, para Justo demostraba cierta coherencia en su problemático vínculo con los símbolos de la política, aunque todo el proceso de su funeral demuestra que en el sentido común socialista predominaba la identificación con el rojo.

Se vuelve patente así el carácter inestable de todo proceso de construcción identitaria, así como el peso de las fuentes originales de las cuales las formaciones político-partidarias extraían sus motivos y creencias fundamentales. De allí que el socialismo, autoconcebido como un movimiento que representaba «ideas», se viera tensionado con sucesivas modulaciones y variaciones, ajustándose a contextos y coyunturas conflictivas e inciertas. Contrariamente a lo que se ha afirmado por

\footnotetext{
${ }^{36} L V, 09,10$ y $11 / 01 / 1928$.

37 «Un gran duelo nacional constituyó la muerte del fundador del Partido Socialista en Argentina», Caras y Caretas, 29/01/1928; «Juan B. Justo», LV, 10/01/1928. Para las disputas simbólicas del legado justista durante su funeral, ver el artículo de Juan Buonuome en este dossier.
} 
la supuesta primacía de su positivismo, como teoría del conocimiento traspolada de forma transparente a la política, Justo demostró una particular sensibilidad a la dimensión simbólica de la política, pero intentando ubicarla en un lugar desprovisto de conflictividad o donde no jugara un papel determinante.

El papel de los símbolos en la subjetivación política de los individuos y las masas retornó una y otra vez en las reflexiones y directivas de Justo, pese a sus no menos recurrentes intentos por desterrarlos del debate político. Después de todo formaban parte de esa realidad sobre la que los socialistas operaban como fuerza que pretendía llevar a cabo una tarea pedagógica de transformación de la sociedad, haciendo uso de ellos. Esta tensión se advierte en las inflexiones que experimentó la joven cultura de izquierdas en Argentina desde la década de I890: las posiciones entre nacionalismo e internacionalismo, el lugar del ps dentro del movimiento obrero, las convicciones que entraron en crisis con el Centenario, la Gran Guerra y sus consecuencias, pero asimismo la sedimentación de creencias sacralizadas que expresaron los dilemas de dirigentes y militantes. Caminos que divergieron y convergieron en el marco de una sociedad móvil que da cuenta del carácter pletórico del socialismo argentino, menos dogmático de lo que se ha aceptado.

La interpretación de Justo sobre los símbolos no muestra una dirección que actúa por una acumulación sucesiva de visiones o lecturas, sino que se fue ajustando diacrónicamente a contextos en donde no siempre las racionalizaciones del intelectual se impusieron sobre la pasión partisana. Al mismo tiempo, las referencias a otros dirigentes permiten conjeturar sobre los continuos puntos de contacto y de fuga entre culturas políticas, sus préstamos mutuos y la centralidad de ciertos valores en determinados momentos, reflejados en los debates que se suscitaron esta vez de forma sincrónica a las intervenciones de Justo.

El principal dirigente del Ps se reveló tempranamente como un partidario del uso racional e incluso emocional de los símbolos, pero evitando el peligro del fanatismo ciego, de la manipulación fetichista y de la sugestión espontaneísta, entre la transparencia superficial que proyectaban y la opacidad emergente de su profundidad que, en casos, volvía misteriosa a la política. Aun cuando negara la importancia de aquellos, proponiendo finalmente eliminarlos, esa misma actitud es una muestra de la carga pasional con que se los pensaba y experimentaba su influencia. Sin embargo, así se le otorgue un lugar preponderante a las concepciones de Justo dentro del socialismo, resulta difícil extraer de ello una causalidad en el devenir de la cultura política de los socialistas argentinos. Primero, por la 
diversidad de posturas con las cuales debió lidiar, en muchos casos, arraigadas de hecho y contra las que él mismo sostuviera desencuentros. Luego, porque lo relacionado con la creciente importancia que comenzaron a ocupar los símbolos en los procesos de constitución de actores colectivos se trataba de una tendencia más general que trascendía al socialismo y la política argentina, un dato que signará las grandes identidades y culturas políticas contemporáneas. El funeral de Justo, cuando una multitud de decenas de miles de personas acompañó su féretro cubierto con banderas, materializó la fusión de las dos caras de quien se convirtió él mismo en un símbolo partidario.

\section{Referencias bibliográficas}

ANGENOT, MARC (1998): «Le drapeau rouge: rituels et discours», en: F. Coblence y B. Eizykman (dirs.), Colloque d'Amiens: L'esthétique de la rue, París, L'Harmattan, pp. 73-100.

ARICÓ, JOSÉ (1999): La hipótesis de Justo. Escritos sobre el socialismo en América Latina, Buenos Aires, Sudamericana.

BELLAMY, RICHARD (2008): "The advent of the masses and the making of the modern theory of democracy», en: T. Ball y R. Bellamy (eds.), The Cambridge History of Twentieth-Century Political Thought, Cambridge, Cambridge University Press, pp. 70-103.

BERSTEIN, SERGE (2006): «Symbolique et politique: nature et fonction des symbols partisans», en: $\mathrm{M}$. Agulhon, A. Becquer y É. Cohen (comps.), La République en répresentations, París, Publications de la Sorbonne, pp. 43-47.

BURRIN, PHILIPPE (1986): «Poings levés et bras tendus. La contagion des symbols au temps du Front Populaire», en: Vingtième Siècle, vol. 11, $n^{\circ} 11$, pp. 5-20.
CALLAHAN, KEVIN (2010): Demonstration culture. European socialism \& the Second International, 1889-1914, Leicester, Troubabor. CAMARERO, HERNÁN (2017): Tiempos rojos. El impacto de la Revolución Rusa en la Argentina, Buenos Aires, Sudamericana.

CASTRO, MARTín (2010): «Para combatir ese extraviado prurito de extranjerismo: políticos católicos, la cuestión nacional y el Consejo nacional de Educación en torno al Centenario», en: M. Castro y M.I. Tato (comps.), Del Centenario al peronismo. Dimensiones de la vida política argentina, Buenos Aires, Biblos, pp. 66-95.

CATTARUZZA, ALEJANDRO (2007): «Historias rojas. Los intelectuales comunistas y el pasado nacional en los años 1930s», en: Prohistoria, no 11, pp. 169-189. CÚNE0, DARDO (1997), Juan B. Justo y las Iuchas sociales en la Argentina, Buenos Aires, Solar. DEL VALLE IBERLUCEA, ENRIQUE (1934): La Revolución Rusa, Buenos Aires, Claridad.

DICKMANN, ADOLFO (1933): Nacionalismo y socialismo, Buenos Aires, Porter Hns. 
DOTTI, JORGE (2009): «Las hermanas-enemigas. Ciencia y ética en el positivismo del Centenario», en: Las vetas del texto, Buenos Aires, Las Cuarenta. EHRLICH, LAURA (2006/2007): «Manuel Ugarte entre el modernismo latinoamericano y el socialismo. Una convivencia difícil», en: Políticas de la Memoria, 6/7, 105-118.

FERNÁNDEZ SEBASTIÁN, JAVIER (2009): «Conceptos y metáforas en la política moderna. Algunas propuestas para una nueva historia político-conceptual», en: J. Canal y J. Moreno Luzón (eds.), Historia cultural de la política contemporánea, Madrid, CEPyC, pp. 11-30.

FIGES, ORLANDO Y KOLONITSKII, BORIS (2001): Interpretar la Revolución Rusa. El lenguaje y los símbolos de 1917, Madrid, Biblioteca Nueva/Universitat de Valencia.

FRANZÉ, JAVIER (1993): El concepto de política en Juan B. Justo, dos tomos, Buenos Aires, Centro Editor de América Latina.

GEERTZ, CLIFFORD ([1973] 2003): «Ethos, cosmovisión y el análisis de los símbolos sagrados», en: La interpretación de las culturas, Barcelona, Gedisa, pp. 118-130.

GELI, PATRICIO Y PRISLEI, LETICIA (1993): «Una estrategia socialista para el laberinto argentino. Apuntes sobre el pensamiento político de Juan B. Justo», en: Entrepasados, n 4/5, pp. 21-39.

JUSTO, JUAN B. ([1898] 1920): «La teoría científica de la historia y la política argentina», en: Socialismo, Buenos Aires, La Vanguardia, pp. 5-34.

JUSTO, JUAN B. ([1902] 1920): «El Socialismo», en: Socialismo, Buenos Aires, La Vanguardia, pp. 37-77. JUSTO, JUAN B. (1909): Teoría y práctica de la Historia, Buenos Aires, Lotito y Barberis.

JUSTO, JUAN B. ([1915] 1933): «Conmemoración de la independencia argentina. Proyecto de ley», en: Internacionalismo y patria, Buenos Aires, La Vanguardia, pp. 79-84.
JUSTO, JUAN B. (1916): «Los nuevos valores éticos. A propósito de la guerra», en: La realización del socialismo, Buenos Aires, La Vanguardia, pp. 80-83. JUSTO, JUAN B. ([1918] 1933): «1º de Mayo de 1918», en: Internacionalismo y patria, Buenos Aires, La Vanguardia, pp. 155-158.

JUSTO, JUAN B. ([1920] 1947): «El momento actual del socialismo», en: La realización del socialismo, Buenos Aires, La Vanguardia, pp. 303-334.

JUSTO, JUAN B. ([1922] 1947): «Unidad obrera», en: La realización del socialismo, Buenos Aires, La Vanguardia, pp. 376-380.

JUSTO, JUAN B. ([1927/928] 1947): «Programa de acción para las juventudes socialistas», en: La realización del socialismo, Buenos Aires, La Vanguardia, pp. 399-406

JUSTO, JUAN B. (1947): La realización del socialismo, Buenos Aires, La Vanguardia.

KORFF, GOTTFRIED (1993): «History of Symbols as Social History? Ten preliminary notes on the image and sign systems of social movements in Germany", en: International Review of Social History, $n^{\circ} 38$, pp. 105-125.

MARTínEZ MAZZOLA, RICARDO (2008): El Partido Socialista y sus interpretaciones del radicalismo argentino (1890-1930), Tesis Doctoral en Historia, Universidad de Buenos Aires.

MICHELS, ROBERT ([1911] 2017): Los partidos políticos. Un estudio sociológico de las tendencias oligárquicas de la democracia moderna, Buenos Aires, Amorrortu.

MOSSE, GEORGE (2007): La nacionalización de las masas. Simbolismo político y movimientos de masas en Alemania desde las guerras napoleónicas al Tercer Reich, Buenos Aires, Siglo XXI.

PALERM0, SILVANA (2016): «Tribunas y panfletos: la primera campaña presidencial del Partido Socialista bajo la ley Sáenz Peña», en: Estudios, $n^{\circ} 36,37-55$. 
PORTANTIERO, JUAN CARLOS (1999): Juan B. Justo. Un fundador de la Argentina moderna, Buenos Aires, Fondo de Cultura Económica.

POY, LUCAS (2014): «Juan B. Justo y el socialismo argentino ante la Primera Guerra Mundial (1909-1915)», en: Política y cultura, n² 42, pp. 155-181.

PRISLEl, LETICIA (2000): «Los intelectuales y el socialismo: Juan B. Justo, el partido y el arte», en: Entrepasados, n 18-19, pp. 53-63.

REYES, FRANCISCO (2016): Identidades militantes. Partido, rituales políticos y nación en los orígenes del radicalismo y del socialismo argentinos (1890-1912), Tesis de Doctorado en Ciencia Política, Universidad Nacional de Rosario.

REYES, FRANCISCO (2018): «La patria es el otro, pero no para siempre. La cuestión de la nación en el socialismo de la Argentina finisecular (18941912», en: Historia y Política, nº 39.

SERAS, SOFÍA (2015): «El culto a los muertos en la construcción de la identidad socialista en la Argentina. Un análisis del semanario La Vanguardia (1894-1905)», en: V Jornadas Nacionales de Historia Social, La Falda, 13-15 de mayo.
SIRINELLI, JEAN-FRANÇOIS (1999): «Elogio de lo complejo», en: J.-P. Rioux y J.-F. Sirinelli (comps.), Para una historia cultural, México DF, Taurus, pp 457-467.

TARCUS, HORACIO (2013): Marx en Argentina. Sus primeros lectores obreros, intelectuales y científicos, Buenos Aires, Siglo XXI.

TATO, MARÍA INÉS (2016): «La cultura política nacionalista en la vorágine de la Gran Guerra», en: Anuario del Instituto de Historia Argentina, vol. $16, \mathrm{n}^{\circ} 2$.

TERÁN, OSCAR (2000): Vida intelectual en el Buenos Aires fin-de-siglo (1880-1910). Derivas de la "cultura científica", Buenos Aires, Fondo de Cultura Económica.

UGARTE, MANUEL (1914): Manuel Ugarte y el Partido Socialista, Buenos Aires, Unión Editorial Hispano-Americana.

UGARTE, MANUEL (2013): Hacia la unidad latinoamericana, Buenos Aires, Punto de Encuentro.

VAN GINDERACHTER, MAARTEN (2009): «Contesting national symbols. Belgian belle époque socialism between rejection and appropriation», en: Social History, vol. 34, n 1, pp. 55-73. 